\title{
Calcium-binding proteins from the outer acrosomal membrane of ram spermatozoa: potential candidates for involvement in the acrosome reaction
}

\author{
S. Sukardi*, R. M. A. Elliott, J. O. Withers, U. Fontaine, \\ J. D. Millar, M. R. Curry and P. F. Watson ${ }^{\dagger}$ \\ Department of Veterinary Basic Sciences, Royal Veterinary College, Royal College Street, \\ London NW1 OTU, UK
}

\begin{abstract}
After an intracellular calcium influx, fusion of the sperm plasma membrane and outer acrosomal membrane (the acrosome reaction) precedes mammalian fertilization in vivo. This study describes the isolation of outer acrosomal membrane from ram spermatozoa and the subsequent characterization of calcium-binding proteins. Pooled ejaculates were diluted, cooled slowly and washed. Incubation with Hyamine 1622 (benzethenium chloride) and subsequent slow centrifugation gently dislodged and concentrated acrosomal membranes, the fragments of which were isolated on a two-step discontinuous sucrose gradient. The acrosomal membrane material stained with Giemsa, whereas spermatozoa from the gradient pellet stained intensely only in the equatorial segment. The acrosomal fraction showed a limited number of polypeptides by SDS-PAGE. Incubation with ${ }^{45} \mathrm{Ca}^{2+}$ revealed two radioactive bands at 34 and $39 \mathrm{kDa}$.
\end{abstract}

Extraction in the presence of EGTA implied that these proteins are not peripheral proteins associated with the membrane only in the presence of calcium ions, but are integral membrane proteins. Polyclonal antisera raised to the two bands showed specific binding to the anterior acrosomal region and demonstrated the intracellular location of the proteins. Sequence data of protein A revealed $83 \%$ homology with calnexin homologue precursor and $70 \%$ homology with annexin XI. Protein B showed $68 \%$ homology with protein SP-10 precursor and $64-72 \%$ homology with various annexins. However, crossreactivity with a range of commercial annexin antibodies and a specific antibody to a synthetic motif encompassing the annexin calcium-binding site was not demonstrable. It is concluded that the isolated proteins are unlikely to be annexins, but are possibly novel calciumbinding proteins.

\section{Introduction}

The acrosome reaction of mammalian spermatozoa is an exocytotic event involving multiple fusions of the outer acrosomal membrane and the overlying plasma membrane (Yanagimachi, 1994). The acrosome reaction is preceded by capacitation, during which the membranes become more readily fusogenic. The separation of capacitation from the subsequent acrosome reaction is indistinct, although the acrosome reaction involves the irreversible fusion of membranes. In vivo, the acrosome reaction is provoked by species-specific agonists associated with the glycoprotein coat of the oocyte, the zona pellucida (Yanagimachi, 1994). During capacitation, the details of which are as yet unclear, phospholipase A2, phospholipase C and protein kinase C are activated, leading to stimulation of signalling pathways

*Present address: Faculty of Veterinary Medicine and Animal Science, Universiti Pertanian Malaysia, 43400 UPM Serdang, Selangor Darul Ehsan, Malaysia

${ }^{\dagger}$ Correspondence

Email: pwatson@rvc.ac.uk and phosphorylation of membrane-active enzymes that destabilize the lipid bilayer (Breitbart et al., 1997). The various pathways of capacitation converge for the fusion reaction of the outer acrosomal membrane and plasma membrane (Harrison, 1996). Initiation of the acrosome reaction depends upon a sperm receptor-ligand recognition of the glycosylated residues on zona protein ZP3 (or its equivalent in a particular species), and a sperm receptor tyrosine kinase binding to the amino acid residues, triggering tyrosine phosphorylation signalling, which leads to a marked increase in intracellular calcium via voltagegated channels (Benoff, 1998).

Much of the cascade of events is calcium-dependent, and the initial events (towards the end of capacitation) may depend on lower concentrations of calcium, possibly micromolar concentrations or lower, whereas the final stages require millimolar concentrations of extracellular calcium (Fraser, 1987; Roldan and Fragio, 1993). The accumulation of calcium ions in the sub-plasma membrane space overlying the acrosome brings about the final approximation of the membrane surfaces and their subsequent fusion. 
At present, there is no clear understanding of the mechanism by which the increased permeability to calcium results in membrane fusion in spermatozoa, although increased disordering of the lipids is clearly involved. Calcium-dependent activation of enzymes such as phospholipase A2 (Roldan, 1998), the activity of which increases the fusigenicity of the relevant membranes, is implicated towards the moment of fusion. One suggestion is that membrane-bound F-actin is depolymerized, allowing the approximation of the two membranes (Spungin et al., 1995; Spungin and Breitbart, 1996). However, there is currently no clear understanding of the mechanism by which fusion is initiated.

Calcium-binding sites have been demonstrated ultrastructurally in the head region of ram spermatozoa using a pyroantimonate technique (Plummer and Watson, 1985); calcium antimonate deposits were seen to localize initially on the outer acrosomal membrane, in particular just anterior to the equatorial segment, a region in which the acrosome reaction appears to be initiated in ram spermatozoa (Fléchon et al., 1986). During the acrosome reaction, the calcium localization appeared to become more evenly dispersed along the anterior outer acrosomal membrane, was associated particularly with sites of approximation of the fusing membranes, but was excluded from the interior of the hybrid vesicles formed by the acrosome reaction (Watson et al., 1995). The close relationship between membrane vesiculation and calcium binding provides support for the hypothesis that a calcium-binding protein is involved in the membrane fusion cascade (Watson and Plummer, 1986). Following on from these studies, the aim of the present study was to isolate and characterize calciumbinding proteins in the outer acrosomal membrane of ram spermatozoa.

\section{Materials and Methods}

\section{Semen collection}

Ejaculated ram semen was collected with an artificial vagina from Friesland rams housed at the Royal Veterinary College.

\section{Isolation of the outer acrosomal membrane}

The acrosomal membrane fraction was prepared essentially using the method of Multamäki (1973) but with some modification. All the reagents used in this procedure were of analytical grade and were purchased from BDH Ltd (Lutterworth). Solutions were supplemented with $1 \mathrm{mmol}$ phenyl methyl sulphonyl fluoride (PMSF) $\mathrm{I}^{-1}$ in isopropanol to inhibit the action of serine proteases. Ejaculates were pooled, diluted with sperm Ringer's solution (Mann, 1964) in a ratio (diluent:semen) of 0.4:1.0, mixed and cooled slowly to $2^{\circ} \mathrm{C}$ at a cooling rate of $0.25^{\circ} \mathrm{C} \mathrm{min}-1$. Hyamine 1622 (benzethenium chloride, $0.05 \%(\mathrm{w} / \mathrm{v})$ ) was used to solubilize the plasma membranes. A two-step discontinuous sucrose gradient ( $2 \mathrm{ml}^{\text {of }} 2.0 \mathrm{~mol} \mathrm{l}^{-1}$ and $3 \mathrm{ml}$ of $1.57 \mathrm{~mol} \mathrm{l}^{-1}$ ) centrifuged at $56000 \mathrm{~g}$ at $2^{\circ} \mathrm{C}$ was used to isolate the acrosomal membrane fraction. The acrosomal membrane fraction was unloaded from the sucrose gradient and centrifuged at $100000 \mathrm{~g}$ at $10^{\circ} \mathrm{C}$ for $30 \mathrm{~min}$.

\section{Giemsa staining}

The sperm pellet from the sucrose gradient and the concentrated outer acrosomal membrane fraction were stained with Giemsa according to the method of Watson (1975).

\section{Acid phosphatase estimation}

Estimation of acid phosphatase, an enzyme that binds to the outer acrosomal membrane (Alison and Hartree, 1970), was carried out according to the method of Walter and Schott (1974).

\section{Protein estimation}

Protein estimations were carried out using either the modified Lowry procedure kit (Sigma Ltd, Poole) or the Micro BCA protein assay (Pierce Inc., Rockford, IL).

\section{Protein separation}

The acrosomal membranes were solubilized in $4 \%(\mathrm{w} / \mathrm{v})$ SDS, 50 mmol Tris-HCl l-1, pH 6.8, and 15\% (v/v) glycerol (Peterson et al., 1989) and stored in aliquots at $-20^{\circ} \mathrm{C}$. Samples were heated for $1 \mathrm{~min}$ at $40^{\circ} \mathrm{C}$ and loaded on to gels. Proteins were separated by SDS-PAGE (Laemmli, 1970) on $15 \%$ separating and $4.5 \%$ stacking gels using the Mini-Protean II kit (Bio-Rad Laboratories Ltd, Hemel Hempstead). Proteins were separated for $45 \mathrm{~min}$ at a constant voltage of $200 \mathrm{~V}$.

\section{Protein transfer (western blotting)}

Gels were equilibrated in transfer buffer containing 20\% $(\mathrm{v} / \mathrm{v})$ methanol, $25 \mathrm{mmol}$ Tris $\mathrm{I}^{-1}$ and $192 \mathrm{mmol}$ glycine $\mathrm{I}^{-1}$, $\mathrm{pH}$ 8.5, for $15 \mathrm{~min}$ before transfer. Separated proteins were blotted according to Towbin et al. (1979) on to $0.45 \mu \mathrm{m}$ nitrocellulose membranes at a constant current of $100 \mathrm{~mA}$ for $65 \mathrm{~min}$ at $4^{\circ} \mathrm{C}$ using the Mini-Trans Blot apparatus (BioRad Laboratories Ltd). Membranes were stained for $1 \mathrm{~min}$ in Amido Black (Sigma Ltd) and stain was removed with 15\% $(\mathrm{v} / \mathrm{v})$ isopropanol and $10 \%(\mathrm{v} / \mathrm{v})$ acetic acid to visualize transferred bands, or membranes were left unstained for autoradiography or immunoblotting.

\section{${ }^{45} \mathrm{Ca}^{2+}$ autoradiography}

The ${ }^{45} \mathrm{Ca}^{2+}$ autoradiography technique was carried out according to Maruyama et al. (1984) and Peterson et al. (1989) with some modification. The membranes were washed twice and incubated in $1 \mathrm{mCi}{ }^{45} \mathrm{Ca}^{2+} \mathrm{I}^{-1}$, washed, dried and exposed for $48 \mathrm{~h}$ to photographic film (Kodak XOMAT AR/Kodak Biomax, Kodak UK, Ltd). The film was developed in GBX-2 developer (Kodak UK, Ltd). 


\section{Preparation of polyclonal antisera}

Protein bands, the positions of which were identified by ${ }^{45} \mathrm{Ca}^{2+}$ labelling on autoradiographs of parallel gels, were excised and eluted. The production of antisera was carried out by Regal Group UK (Chapel Lane, Great Bookham, Surrey) for 17 weeks. Five immunizations, consisting of an initial immunization combined with Freund's complete adjuvant and four subsequent immunizations combined with Freund's incomplete adjuvant, were carried out on two rabbits (one antigen per rabbit). The antiserum from three test bleeds and the terminal bleed were assayed for antibody specificity.

\section{Visualization of antisera}

Diluted ram semen suspension was washed using the syringe-filter method of Sukardi et al. (1997) and was smeared on to slides. The cells were dried and permeabilized with saponin $\left(150 \mu \mathrm{g} \mathrm{ml}^{-1}, 3 \mathrm{~min}\right.$; Sigma) and washed twice in PBS. Sheep serum (1\%, $30 \mathrm{~min})$ was added to block non-specific binding sites and the slides were washed twice in PBS. The slides were incubated for 1 $\mathrm{h}$ with antibody to one of the protein bands and washed twice in PBS. Secondary fluorescein isothiocyanate conjugated (FITC-conjugated) anti-rabbit IgG was added and the slides were incubated for $1 \mathrm{~h}$ in the dark. The slides were washed twice in PBS, drained and wet mounted. The cells were viewed immediately with an Olympus BHS fluorescence microscope at $\times 40$ magnification and photographed using ASA 400 slide film.

\section{Affinity purification of antisera}

After the subcellular fractionation of spermatozoa, the fractions demonstrated to be non-outer acrosomal membrane were pooled and placed on to a further two-step discontinuous sucrose gradient to remove any remaining outer acrosomal membrane. The polyclonal antisera were incubated with non-outer acrosomal membrane material for $30 \mathrm{~min}$ at room temperature. The suspensions were centrifuged at $900 \mathrm{~g}$ for $15 \mathrm{~min}$ and the supernatant containing the antibodies was decanted and saved.

\section{Binding of affinity purified antibodies to the calcium- binding proteins}

Specificity of affinity purified antibodies was examined alongside the crude antisera and pre-immune sera by incubating the antibodies on slides with ram semen, as described earlier.

\section{Localization of calcium-binding proteins to outer acrosomal membrane}

Spermatozoa were permeabilized by cold-shock treatment or with $100 \%$ ethanol; other aliquots were nonpermeabilized. Samples of permeabilized and nonpermeabilized cells were stained either with FITC-labelled
Pisum sativum agglutinin (FITC-PSA; an acrosomal status stain) or with primary antibodies to the two proteins and FITC-conjugated secondary antibodies. Other samples were treated with the viability stain propidium iodide. Slides with these treatments were prepared as described earlier.

\section{Amino acid sequencing}

Bands on the western blot were excised, washed in methanol and air dried. The bands were inserted into the blot cartridge of the gas phase automatic sequencer to determine the $\mathrm{N}$-terminal sequence. For internal sequences, the band was treated for $20 \mathrm{~h}$ with cyanogen bromide $(100 \mu \mathrm{g}$ in $100 \mu \mathrm{l}$ of $98 \%$ (v/v) formic acid) in the vapour phase after wetting in $10 \mathrm{mg}$ Biobrene lubricant $\mathrm{ml}^{-1}$ (Applied Biosystems, Foster City, CA) to provide the aqueous environment for cleavage.

\section{Immunodetection}

A commercially available monoclonal human annexin IV antibody (Chemicon Inc., Temecula, CA) and a monoclonal annexins antibody kit containing antibodies for annexins I, II, II light chain, IV and VI raised in mice from a lysate of human fibroblasts (Chemicon Inc.) were used to test for possible crossreactivity with the proteins of interest. In addition, an antibody raised to a portion of the calciumbinding sequence of the annexins (AMKGLGTDE) was made available to us to test our sequences. The enhanced chemiluminescent (ECL) immunodetection kit and protocol (horseradish peroxidase reaction; Amersham UK Ltd) or the Tropix chemiluminescence protocol (alkaline phosphatase reaction; Perkin-Elmer UK, Warrington) were used for antibody localization.

\section{Results}

\section{Membrane separation and identification}

Four bands were seen after centrifugation of the sucrose gradient. The pellet at band I, at the bottom of the tube, consisted mostly of sperm heads without acrosomes. Band II, lying above the first gradient, consisted of sperm mid-pieces and tails. Band III, the acrosome-rich fraction, consisted of two closely associated layers of cellular material lying at the second step of the gradient. The lower coarser layer consisted of cap-like or shrunken acrosomes, whereas the fluffy upper part contained mainly acrosomal remnants. Band IV, lying above the second gradient, comprised the remaining soluble elements of the preparation.

Several tests were performed to confirm that the isolated acrosomal fraction contained essentially outer acrosomal membrane. Firstly, the material was stained with Giemsa stain which, in whole cells, stains the acrosome dark blue-purple (Fig. 1a). After Hyamine treatment, the acrosomes were observed to separate from the cells (Fig. 1b). The isolated membrane fraction stained intensely with Giemsa (Fig. 1c). Similar staining of the cell nucleus fraction 

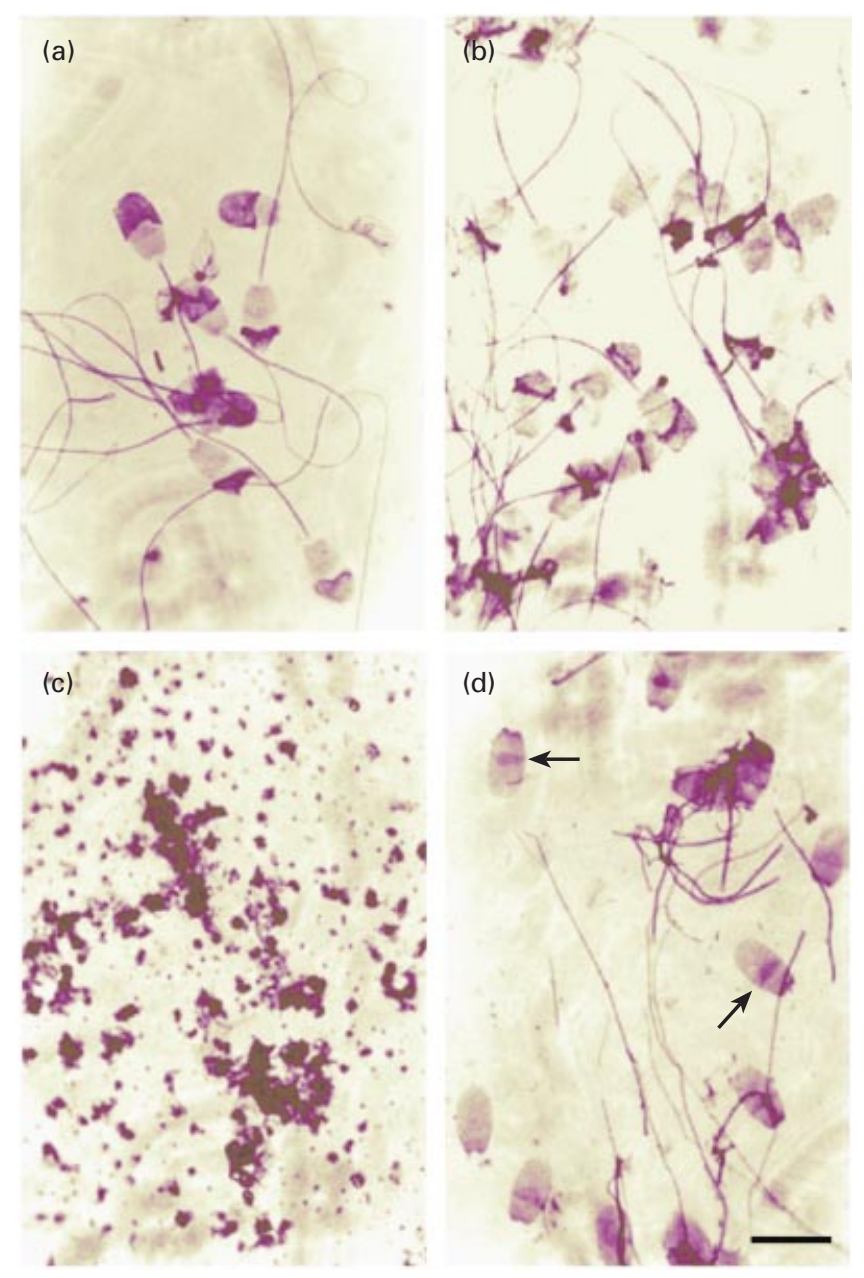

Fig. 1. Sperm material during isolation of the outer acrosomal membrane fraction from ram spermatozoa. Acrosomal membranes stained intensely with Giemsa. (a) After cooling, acrosomes enveloped the rostral portion of the sperm heads. (b) After treatment with Hyamine, the acrosomal membranes separated from the sperm head. (c) Acrosomal membrane fraction showing intense staining with Giemsa. (d) Sperm pellet showing sperm heads with only the equatorial segment of acrosomes (arrows) still attached. Scale bar represents $10 \mu \mathrm{m}$.

together with tails (from the bottom of the gradient) showed that the acrosome was missing from most of these cells with the exception of the equatorial region (Fig. 1d).

The acid phosphatase activity was 3.5-fold greater in the acrosomal fraction compared with that in the whole cell preparation on a constant protein basis, indicating considerable enrichment of the acrosome fraction $(P<0.05)$. However, after membrane separation, the sperm pellet did not have a significantly lower activity than that of the whole cells, indicating that this fraction was probably still contaminated with acrosomal membrane material that had failed to separate.

\section{Protein separation}

A polyacrylamide gel from the electrophoresis of acrosomal membranes is shown (Fig. 2a). Tropomyosin, troponin and calmodulin were included as controls. Major bands were seen of approximately 11, 33, 39, 56, 68, 127 and $147 \mathrm{kDa}$. The corresponding autoradiograph of ${ }^{45} \mathrm{Ca}^{2+}$ bound to the western blot (Fig. 2b) showed that the calcium bound to only two bands, the 33 and $39 \mathrm{kDa}$ bands (subsequently referred to as protein $\mathrm{A}$ and $\mathrm{B}$ ). The autoradiograph also identified troponin and calmodulin, but failed to show tropomyosin, which does not bind calcium. It should be noted that the proteins were separated in a non-reducing environment; when mercaptoethanol or dithiothreitol was included calcium binding did not occur.

\section{Nature of membrane attachment}

The acrosomal membrane fraction was prepared in the presence of 2 or $5 \mathrm{mmol}^{\mathrm{EGTA} \mathrm{I}}{ }^{-1}$ to determine whether membrane association was dependent on the presence of $\mathrm{Ca}^{2+}$. No difference was seen on the gels prepared from these samples compared with membranes prepared in the standard way (data not shown). The protein bands shown to bind calcium were present when $\mathrm{Ca}^{2+}$ was sequestered by EGTA.

\section{Localization of calcium-binding proteins to the outer acrosomal membrane}

The binding of the FITC-conjugated secondary antibody to spermatozoa confirmed the presence and therefore successful generation of polyclonal antibodies to proteins $\mathrm{A}$ and B. The result for protein B is shown (Fig. 3a); similar results were obtained for protein A. Pre-immune sera did not bind. Optimum results were obtained with primary antibody diluted 1:450 and secondary antibody diluted 1:1000.

Non-outer acrosomal membrane material derived from $>500 \times 10^{6}$ spermatozoa $\mu l^{-1}$ crude antibody was necessary to remove non-acrosomal specific binding. With purified antibody B preparation, binding was restricted to the acrosomal region (Fig. 3b). The results with both antibodies were similar.

Permeabilized cells, whether cold-shocked or ethanoltreated, showed propidium iodide staining of all the cells, confirming the degree of permeabilization. Clear staining of acrosomal material by FITC-PSA, a lectin that labels the acrosomal material specifically, demonstrated the presence of intact acrosomes. Antibodies to the two calcium-binding proteins, as visualized by FITC-conjugated secondary antibody, had clearly bound intracellularly, as there was no evidence of staining by either antibody to cells not subjected to either of the permeabilization methods. Lack of propidium iodide staining of these cells also demonstrated the integrity of the plasma membranes. The staining pattern of non-permeabilized cells by FITC-PSA was weak. 


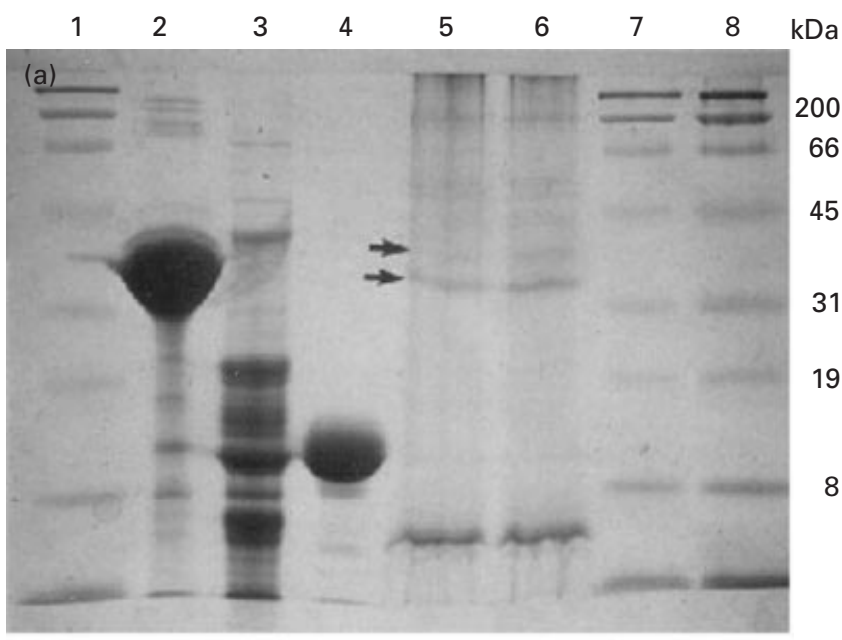

(b)

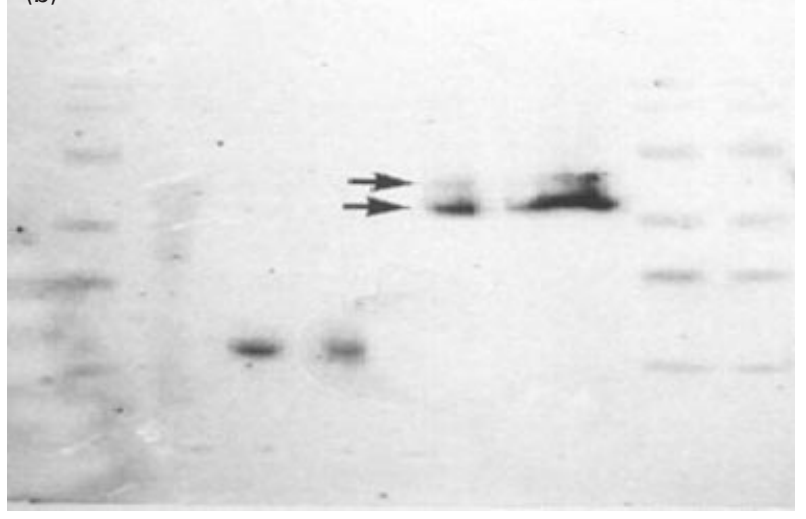

Fig. 2. (a) Stained SDS-PAGE gel of outer acrosomal membrane proteins from ram spermatozoa. Lane 1: standards; lane 2: tropomyosin; lane 3: troponin; lane 4: calmodulin; lanes 5 and 6: outer acrosomal membrane; lanes 7 and 8: standards. (b) Autoradiograph of blot after exposure to ${ }^{45} \mathrm{Ca}^{2+}$. Arrows indicate outer acrosomal membrane bands that bind calcium.

\section{Sequencing}

Samples of proteins A and B were isolated and recovered from gels to obtain sequence data to assist in their identification. The $\mathrm{N}$-terminal sequence of 11 amino acids for protein A was as follows: Ala-Pro-Val-Ala-Val-AsptcPhe-Met-Pro-Pro-Val. The sequence has $83 \%$ homology with calnexin homologue precursor, $77 \%$ homology with a rabbit annexin $\mathrm{XI}$ and $70 \%$ homology with two variants of bovine annexin XI. Homology (69-76\%) was also detected between this protein and other annexins I, IV, V, VI and VII from various animal and plant species.

No N-terminal sequence could be obtained for protein B. However, after cyanogen bromide cleavage of the protein, an internal sequence (15 amino acids) was obtained as follows: X-Pro-Phe-X-Phe-Glutc-Asp-Arg-AspLeu-Glu-Phe-Met-His-Glu ( $\mathrm{X}=$ unknown). The sequence was found to have $68 \%$ homology with acrosomal protein
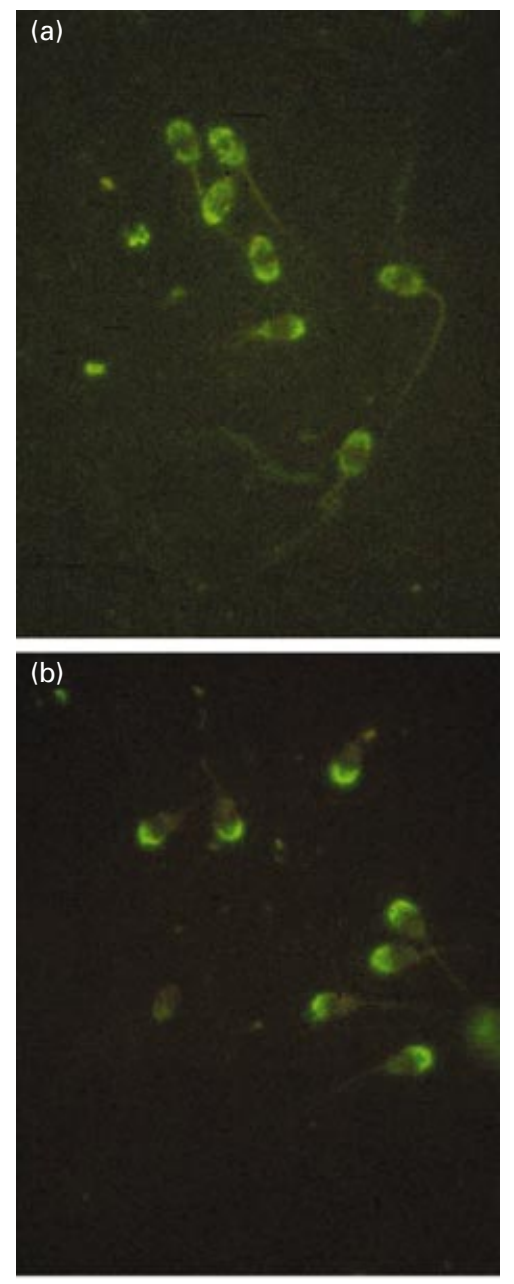

Fig. 3. Immunolocalization of polyclonal antibody to protein B. (a) Crude antibody probing of permeabilized ram spermatozoa showing labelling of the acrosome and the post-acrosomal region. (b) Immuno-purified antibody B labelled the acrosome specifically.

SP-10 precursor, $72 \%$ homology with human annexin VIII and $64-70 \%$ homology with annexins I-III, V-VIII and $\mathrm{XI}-\mathrm{XIII}$ in various animal and plant species.

\section{Immunodetection}

The immunodetection procedure using both commercial antibody to annexin IV and the multiple annexin antibody kit to human annexins revealed very strong binding to the positive controls but no binding to proteins $\mathrm{A}$ and $\mathrm{B}$ (not illustrated). None of the acrosomal membrane proteins bound the antibodies. When the antibody specific to the calcium-binding domain of annexins was crossreacted, proteins A and B remained unlabelled, although a band of lower molecular mass did stain and was clearly distinguishable from proteins A and B (Fig. 4). 


\section{Discussion}

Multamäki (1973) published a method of purifying acrosomes from bull spermatozoa using a cationic detergent, Hyamine 2389 (methyl-dodecyl-benzyltrimethylammonium chloride and methyl-dodecyl xylene bistrimethylammonium chloride). Similar results were obtained in the present study with another cationic detergent, Hyamine 1622 (benzethenium chloride). The method involved cooling and washing at $2{ }^{\circ} \mathrm{C}$, which resulted in loosening of the acrosomes. The detergent served to solubilize the plasma membranes and the subsequent repeated centrifugation at low speed dislodged and concentrated the detaching acrosomes together with considerable contaminating cell debris. Separation on the sucrose gradient finally isolated a purified acrosomal membrane fraction containing two closely associated bands, one consisting of acrosomal 'ghosts' (complete outer acrosomal membrane sheaths) and the other consisting of acrosomal membrane fragments; these two bands were combined to form the acrosomal membrane fraction. Outer acrosomal membranes obtained were enriched and concentrated as evidenced by the Giemsa staining. Acrosomes were absent from most of the cells in the pellet, confirming the efficacy of the isolation method. The intact equatorial segment indicated rupture of the outer acrosomal membrane at its anterior border, a situation confirmed by electron microscopy (not illustrated). The isolated portions of acrosomal membrane are those involved in the exocytotic event that is the acrosome reaction, and are the regions in which localization of calcium is known to occur (Watson and Plummer, 1986; Watson et al., 1995).

The isolated membrane fraction showed a considerable enrichment for acid phosphatase, a marker enzyme for acrosomal membrane (Alison and Hartree, 1970). The fact that the sperm pellet from the sucrose gradient did not show reduced acid phosphatase activity compared with the control cells was unexpected. It is clear that not all acrosomal material was separated in the preparation stage, and any that remained attached would have accumulated with the cell remnants in the pellet.

Only seven major bands were detected by electrophoresis of the solubilized proteins of the outer acrosomal membranes. This finding is in agreement with results from other species (TopferPetersen et al., 1983; Olson et al., 1985, 1987). When the gels were stained with silver many more minor bands were evident (data not shown), but of the major bands only those at 34 and 39 kDa demonstrated calcium-binding ability by autoradiography; the fact that calcium was also bound by calmodulin and troponin but not by tropomyosin showed that the method was working satisfactorily. The two proteins identified, A and B, were present in different quantities: protein $\mathrm{A}$ was present at a higher concentration in the fraction. Destruction of the calcium binding by reducing agents showed that calcium binding was dependent on the tertiary structure of the proteins.

The permeabilization of sperm plasma membranes and the subsequent binding of the affinity purified antibodies (a)

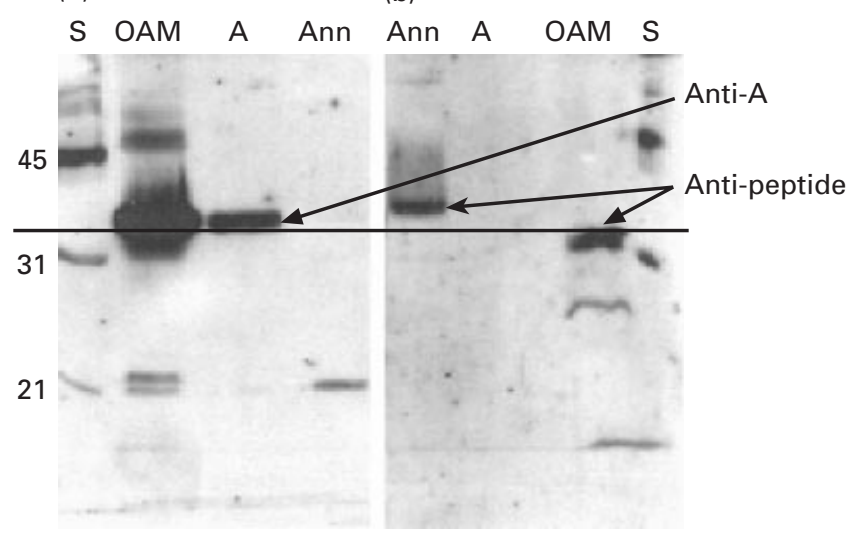

Fig. 4. Two halves of the same blot of SDS-PAGE separated outer acrosomal membrane proteins and isolated protein $A$ from ram spermatozoa. (a) Stained with antibody A; (b) stained with antipeptide of annexin endonexin calcium-binding motif. S: standards; OAM: outer acrosomal membrane fraction; Ann: annexin positive control (prepared from bovine lung tissue); A: isolated protein A. A straight line drawn across the blot emphasizes the difference in molecular masses between the band reacting to the anti-peptide and the band of protein A.

confirmed the localization of proteins $\mathrm{A}$ and $\mathrm{B}$ to the acrosomal region of the sperm head. Failure of the antibodies to bind to non-permeabilized cells indicated the intracellular location of the two proteins and demonstrated that it was unlikely that the antibodies shared any similarity to sperm surface antigens. A study by Cross et al. (1986) demonstrated PSA binding to acrosomal contents, specifically alphamannoside, thereby identifying the presence of the acrosome in permeabilized, acrosome-intact cells. The binding of FITCPSA to the acrosomal contents demonstrated the effectiveness of the permeabilization method and the presence of the acrosomal material still bound by acrosomal membranes. The calcium-binding protein bands do not correspond in terms of molecular mass to calmodulin, a calcium-binding protein that is associated with the acrosomal region of spermatozoa (Jones et al., 1980; Camatini et al., 1986; Trejo and Mújica, 1990). Furthermore, calmodulin is usually considered to be a cytosolic protein.

Calcium is fundamental to many aspects of sperm function, including activation and the acrosome reaction. Changes in cytosolic $\mathrm{Ca}^{2+}$ concentrations evoke a wide range of cellular responses and intracellular calcium-binding proteins are the key molecules in transduction of $\mathrm{Ca}^{2+}$ signalling via enzymatic reactions or modulation of proteinprotein interactions (Niki et al., 1996). Most calcium-binding proteins possess an EF hand domain, an endonexin fold or a $\mathrm{C} 2$ region. Members of the EF hand protein family, which includes calmodulin, troponin and the $\mathrm{S} 100$ proteins, are located mainly within the cytoplasm and nucleus. Calciumphospholipid-binding proteins are divided into the annexins, which commonly possess four repeats of the endonexin fold 
domain (actual calcium binding sites), and the C2 region proteins, which are responsible for calcium-phospholipiddependent activation of protein kinase $\mathrm{C}$. There are also calcium storage proteins with a relatively low affinity for $\mathrm{Ca}^{2+}$ (Niki et al., 1996).

The $\mathrm{N}$-terminal sequence for protein $\mathrm{A}$ indicated that it might be related to calnexin. Calnexin is a membranebound molecular chaperone of the endoplasmic reticulum, binding other proteins temporarily (Bergeron et al., 1994); a testis-specific variant, calmegin, has been proposed to play a role in sperm adhesion to the zona pellucida (Ikawa et al., 1997). Calmegin has not been associated with the acrosome, although its relationship with the endoplasmic reticulum indicates that it may be involved in the assembly of acrosomal contents in the testis. The internal sequence for protein $\mathrm{B}$, although of only a limited number of amino acids, indicated a similarity to SP-10, an intra-acrosomal protein that is not an integral protein of the acrosomal membrane (Foster and Herr, 1992). Human SP-10 consists of a range of polypeptides from 18 to $34 \mathrm{kDa}$ (Herr et al., 1990a), and protein B is outside this range. Moreover, its species incidence is variable: it is present in primates and pigs but not in rabbits, bulls, rats, guinea-pigs or cats (Herr et al., 1990b).

The other groups of proteins showing sequence similarity to the proteins identified are the annexins (Seaton and Dedman, 1998). There are several reasons why the proteins of interest might be related to annexins. This family of proteins is associated with a range of cellular functions, including membrane-membrane interactions and fusion. Annexins have also been implicated in exocytosis (Creutz, 1992). Annexins I-V lie within the molecular range of 30-40 kDa (Moss, 1992). In ram spermatozoa, annexin I is present on the post-acrosomal region and flagellum, and annexin II is present on the equatorial segment and flagellum (Feinberg et al., 1991). Calelectrin (annexin IV) is present in spermatozoa and has molecular masses of 32.5, 35.0 and $67.0 \mathrm{kDa}$, which are in the same range as those of the bands identified in the present study (Südhof, 1984), but its function in spermatozoa is still unknown. However, for the proteins identified in the present study, it was not possible to demonstrate specificity to a commercially available monoclonal annexin IV or to a commercial kit of monoclonal anti-annexin antibodies I, II, II light chain, IV and $\mathrm{VI}$, all raised against human annexins. The EGTA isolation experiment also failed to support the contention that the proteins are annexins, which are generally linked to membranes only in the presence of $\mathrm{Ca}^{2+}$ (Seaton and Dedman, 1998); the proteins of interest remained in the membrane fraction in the absence of $\mathrm{Ca}^{2+}$. Furthermore, the specific antibody to the calcium-binding motif of annexin failed to react with the bands on the western blot associated with the calcium-binding proteins. Therefore, it is apparent that these proteins are not annexins, and they are also dissimilar to the sp50 protein identified by Hernández et al. (1996).

Mechanisms proposed for membrane fusion evoke processes involving fusion proteins that act both to bring membranes into close apposition and to destabilize the phospholipids to facilitate the necessary reorganization. White (1992) defines a fusion protein as an integral membrane protein which, when triggered, undergoes a change in conformation exposing a hydrophobic domain which promotes mixing of lipid components from two apposed bilayers. Calcium could be involved either in stimulating the conformational change or in bringing the membranes into apposition.

Earlier studies demonstrated a close relationship between calcium and the outer acrosomal membrane and the progress of the acrosome reaction (Plummer and Watson, 1985; Watson and Plummer, 1986). The present study has identified outer acrosomal membrane proteins that bind calcium. However, no obvious relationship to known types of calcium-binding protein was found. Whether these two proteins are modifications of the same molecule remains to be determined, as does their functional role. These proteins are possibly novel calcium-binding proteins that are potentially involved in the exocytotic events of the acrosome reaction.

The authors are indebted to J. Walker, Department of Biochemistry, University of Leeds, for the generous gift of the peptide antibody, and to H. D. M. Moore, Department of Molecular Biology and Biotechnology, University of Sheffield, for the determination of amino acid sequences. The authors are also grateful for the expert advice of P. D. Chantler and A. Moore. The technical assistance of J. C. S. Bredl is greatly appreciated. S. Sukardi was a recipient of a Malaysian Federal Government Scholarship and is attached to Universiti Pertanian Malaysia. R. M. A. Elliott was supported by a BBSRC studentship.

\section{References}

Alison AC and Hartree EF (1970) Lysosomal enzymes in the acrosome and their possible role in fertilization Journal of Reproduction and Fertility $\mathbf{2 1}$ 501-515

Benoff S (1998) Modelling human sperm-egg interactions in vitro: signal transduction pathways regulating the acrosome reaction Molecular and Human Reproduction 4 453-471

Bergeron JJ, Brenner MB, Thomas DY and Williams DB (1994) Calnexin: a membrane-bound chaperone of the endoplasmic reticulum Trends in Biochemical Sciences 19 124-128

Breitbart H, Rubinstein S and Lax Y (1997) Regulatory mechanisms in acrosomal exocytosis Reviews of Reproduction 2 165-174

Camatini M, Anelli G and Casale A (1986) Immunocytochemical localization of calmodulin in intact and acrosome-reacted boar sperm European Journal of Cell Biology 41 89-96

Creutz CE (1992) The annexins and exocytosis Science 258 924-931

Cross NL, Morales P, Overstreet JW and Hanson FW (1986) Two simple methods for detecting acrosome-reacted human sperm Gamete Research 15 213-226

Feinberg JM, Rainteau DP, Kaetzel MA, Dacheux J-L, Dedman JR and Weinman SJ (1991) Differential localization of annexins in ram germ cells: a biochemical and immunocytochemical study Journal of Histochemistry and Cytochemistry 39 955-963

Fléchon JE, Harrison RA, Fléchon B and Escaig J (1986) Membrane fusion events in the $\mathrm{Ca}^{2+} /$ ionophore-induced acrosome reaction of ram spermatozoa Journal of Cell Science 81 43-63

Foster JA and Herr JC (1992) Interactions of human sperm acrosomal protein SP-10 with acrosomal membranes Biology of Reproduction 46 981-990 
Fraser LR (1987) Minimum and maximum extracellular $\mathrm{Ca}^{2+}$ requirements during mouse sperm capacitation and fertilization in vitro. Journal of Reproduction and Fertility 81 77-89

Harrison RAP (1996) Capacitation mechanisms, and the role of capacitation as seen in eutherian mammals Reproduction, Fertility and Development 8 581-594

Hernández EO, Roa-Espitia AL, Trejo JC and Mújica A (1996) Sperm protein (sp50) binds to acrosome and plasma membranes in a $\mathrm{Ca}^{2+}$ dependent manner: possible role in acrosome reaction Molecular Reproduction and Development 43 366-375

Herr JC, Flickinger CJ, Homyk M, Klotz K and John E (1990a) Biochemical and morphological characterization of the intra-acrosomal antigen SP10 from human sperm Biology of Reproduction 42 181-193

Herr JC, Wright RM, John E, Foster J, Ays T and Flickinger CJ (1990b) Identification of human acrosomal antigen SP-10 in primates and pigs Biology of Reproduction 42 377-382

Ikawa M, Wada I, Kominami K, Watanabe D, Toshimori K, Nishimune Y and Okabe $\mathbf{M}$ (1997) The putative chaperone calmegin is required for sperm fertility Nature London 387 607-611

Jones HP, Lenz RW, Palevitz A and Cormier MJ (1980) Calmodulin localization in mammalian spermatozoa Proceedings National Academy of Sciences USA 77 2772-2776

Laemmli UK (1970) Cleavage of structural proteins during the assembly of the head of bacteriophage T4 Nature 227 680-685

Mann T (1964) The Biochemistry of Semen and the Male Reproductive Tract Methuen, London

Maruyama K, Mikawa T and Ebashi S (1984) Detection of calcium binding proteins by ${ }^{45} \mathrm{Ca}$ autoradiography on nitrocellulose membrane after sodium dodecyl sulfate gel electrophoresis Journal of Biochemistry 95 $511-519$

Moss SE (1992) The annexins. In The Annexins pp 5-12 Ed. SE Moss. Portland Press Ltd, London

Multamäki S (1973) Isolation of pure acrosomes by subcellular fractionation of bull spermatozoa International Journal of Fertility 18 193-205

Niki I, Yokokura H, Sudo T, Kato M and Hidaka H (1996) $\mathrm{Ca}^{2+}$ signalling and intracellular $\mathrm{Ca}^{2+}$ binding proteins Journal of Biochemistry 120 685-698

Olson GE, Winfrey VP, Garbers D and Noland TD (1985) Isolation and characterization of a macromolecular complex associated with the outer acrosomal membrane of bovine spermatozoa Biology of Reproduction 33 761-779

Olson GE, Winfrey VP, Winer MA and Davenport GR (1987) Outer acrosomal membrane of guinea pig spermatozoa: isolation and structural characterization Gamete Research 17 77-94

Peterson RN, Chaudhry P and Tibbs B (1989) Calcium-binding proteins of boar spermatozoan plasma membranes: identification and partial characterization Gamete Research 23 49-60

Plummer JM and Watson PF (1985) Ultrastructural localization of calcium ions in ram spermatozoa before and after cold shock as demonstrated by a pyroantimonate technique Journal of Reproduction and Fertility $\mathbf{7 5}$ 255-263
Roldan ERS (1998) Role of phospholipases during sperm acrosomal exocytosis Frontiers in Bioscience 3 d1109-d1119

Roldan ER and Fragio C (1993) Phospholipase A2 activation and subsequent exocytosis in the $\mathrm{Ca}^{2+} /$ ionophore-induced acrosome reaction of ram spermatozoa Journal of Biological Chemistry 268 13 962-13970

Seaton BA and Dedman JR (1998) Annexins Biometals 11 399-404

Spungin B and Breitbart H (1996) Calcium mobilization and influx during sperm exocytosis Journal of Cell Science 109 1947-1955

Spungin B, Margalit I and Breitbart H (1995) Sperm exocytosis reconstructed in a cell-free system. Evidence for the involvement of phospholipase $\mathrm{C}$ and actin filaments in membrane fusion Journal of Cell Science $1082525-2535$

Südhof TC (1984) The calelectrins: new and ubiquitous $\mathrm{Ca}^{2+}$-regulated proteins with a possible role in cytotic processes Biochemical Society Transactions 12 972-974

Sukardi S, Curry MR and Watson PF (1997) Simultaneous detection of the acrosomal status and viability of incubated ram spermatozoa using fluorescent markers Animal Reproduction Science 46 89-96

Töpfer-Petersen E, Schmoeckel C and Schill WB (1983) The acrosomal membrane system of boar spermatozoa - morphological and biochemical studies Andrologia 15 62-70

Towbin H, Staehelin T and Gordon J (1979) Electrophoretic transfer of proteins from polyacrylamide gels to nitrocellulose sheets: procedure and some applications Proceedings National Academy of Sciences USA 76 4350-4354

Trejo R and Mújica A (1990) Changes in calmodulin compartmentalization throughout capacitation and acrosome reaction in guinea pig spermatozoa Molecular Reproduction and Development 26 366-376

Walter K and Schott C (1974) Acid and alkaline phosphatase in serum (twopoint method). In Methods of Enzymatic Analysis pp 856-870 Ed. HU Bergmeyer. Academic Press, New York

Watson PF (1975) Use of a Giemsa stain to detect changes in the acrosomes of frozen ram spermatozoa Veterinary Record 97 12-15

Watson PF and Plummer JM (1986) Relationship between calcium binding sites and membrane fusion during the acrosome reaction induced by ionophore in ram spermatozoa Journal of Experimental Zoology 238 113-118

Watson PF, Plummer JM, Jones PS and Bredl JC (1995) Localization of intracellular calcium during the acrosome reaction in ram spermatozoa Molecular Reproduction and Development 41 513-520

White JM (1992) Membrane fusion Science 258 917-924

Yanagimachi R (1994) Mammalian fertilization. In The Physiology of Reproduction pp 189-318 Eds E Knobil and JD Neill. Raven Press, New York

Received 3 May 2001

First decision 17 July 2001.

Accepted 29 August 2001. 